Article

\title{
Corrosion Inhibition Performances of Imidazole Derivatives-Based New Ionic Liquids on Carbon Steel in Brackish Water
}

\author{
Megawati Zunita ${ }^{1, *(1)}$, Deana Wahyuningrum ${ }^{2}$, Buchari ${ }^{2}$, Bunbun Bundjali ${ }^{2}$, I Gede Wenten ${ }^{1}$ \\ and Ramaraj Boopathy ${ }^{3, * \mathbb{D}}$ \\ 1 Chemical Engineering Department, Faculty of Industrial Technology, Institut Teknologi Bandung, \\ Jalan Ganesha 10, Bandung 40132, Indonesia; igw@che.itb.ac.id \\ 2 Chemistry Department, Faculty of Mathematics and Natural Sciences, Institut Teknologi Bandung, \\ Jalan Ganesha 10, Bandung 40132, Indonesia; deana@chem.itb.ac.id (D.W.); buchari@chem.itb.ac.id (B.); \\ bunbun@chem.itb.ac.id (B.B.) \\ 3 Biological Sciences Department, Nicholls State University, Thibodaux, LA 70301, USA \\ * Correspondence: m.zunita@che.itb.ac.id (M.Z.); ramaraj.boopathy@nicholls.edu (R.B.); \\ Tel.: +62-8782-2231-696 (M.Z.); +1-(985)-448-4716 (R.B.)
}

Received: 30 August 2020; Accepted: 9 October 2020; Published: 12 October 2020

\begin{abstract}
In this study, imidazole derivative-based new ionic liquids were investigated as corrosion inhibitors. These new ionic liquids (ILs) are 1,3-dipropyl-2-(2-propoxyphenyl)-4,5-diphenylimidazole iodide (IL1) and 1,3-dibutyl-2-(2-butoxyphenyl)-4,5-diphenylimidazole iodide (IL2). The corrosion inhibition effects of two new ILs were observed on carbon steel in brackish water media $(1 \% \mathrm{NaCl}$ solution). Carbon steel coupons were exposed to $1 \% \mathrm{NaCl}$ solution with various concentrations of ILs. Corrosion inhibition effects were tested by the electrochemical impedance spectroscopy (EIS) method and the Tafel method at various temperatures ranging from $25{ }^{\circ} \mathrm{C}$ to $55{ }^{\circ} \mathrm{C}$. The results showed that ILs have potential as corrosion inhibitors and the adsorption mechanisms of IL1 and IL2 on carbon steel surfaces were also determined, which followed the Langmuir adsorption isotherm model. Acquisition of $\Delta G_{\text {ads }}$ values of IL1 and IL2 were -35.04 and $-34.04 \mathrm{~kJ} / \mathrm{mol}$, respectively. The thermodynamic data of the ILs show that semi-chemical and or physical adsorptions occurred on carbon steel surfaces.
\end{abstract}

Keywords: new ionic liquids; imidazole derivatives; inhibitor corrosion; brackish water

\section{Introduction}

Carbon steel is used significantly in many industrial applications due to its excellent mechanical properties [1-3]. Primarily, carbon steel pipes are used to transfer crude oil which contains corrosive agents and are usually placed under the sea in the oil and gas industry. Corrosive agents in crude oil and brackish water include salts, water, oxygen, acidic, and basic compounds [4,5]. They promote the corrosion reactions, which occur on the internal and the external surfaces of carbon steel pipes. To solve these corrosion problems, corrosion experts prevent and reduce the corrosion rate of carbon steel by cathodic and anodic protection, the coating of the carbon steel surface, and using corrosion inhibitors $[3,4,6,7]$. The isolation of carbon steel surfaces from corrosion agents is an effective strategy to prevent electrochemical corrosion [4,8]. Among several corrosion prevention methods commonly used, the use of corrosion inhibitor is an effective method and the most appropriate way to prevent corrosion [9-12].

A corrosion inhibitor is a compound which can reduce the corrosion rate on the metal surface $[4,13]$. The efficiency of corrosion inhibitors is usually related to the presence of polar functional groups 
with $\mathrm{S}, \mathrm{O}$ or $\mathrm{N}$ atoms in the molecule, heterocyclic compounds, and $\pi$ electrons [9]. Polar functional groups are considered as the reaction centers for the establishment of the adsorption process between corrosion inhibitors and carbon steel surfaces. However, the corrosion inhibitor is expensive, volatile, toxic, and unstable at high temperatures $[14,15]$. Therefore, the recent focus of research is to make environmentally friendly corrosion inhibitors, which have a low environmental risk. The use of an organic compound is one of the best candidates as a raw material to make environmentally friendly corrosion inhibitors [4,6-18].

An organic compound-based corrosion inhibitor has several advantages, such as being environmentally friendly, relatively inexpensive, and having more effective inhibitor performance $[19,20]$. Imidazole and its derivatives have potential as a corrosion inhibitor due to their nitrogen $(\mathrm{N})$ atomic functional groups and free electrons in their $\mathrm{N}$ atom able to interact with carbon steel to protect from corrosion attacks [11,20]. Corrosion inhibitors are developed from new materials including changing the imidazole and its derivative into an ionic liquid (IL) [21].

IL is an organic or inorganic salt, which has a low melting point (under $100^{\circ} \mathrm{C}$ ), non-flammable, and stable at high temperatures [7,17,22-27]. ILs are effective and useful in corrosion engineering and also as an outstanding candidate material in molecular designing and engineering [28]. ILs have very low vapor pressure, which makes them eco-friendlier and less hazardous inhibitors of metal corrosion [16-18,29-32]. In the last decade, many ionic liquids [33] were developed and applied in the corrosion field. Lisac et al. [5] reported an imidazole derivative-based IL (e.g., 4-methyl imidazole) as a corrosion inhibitor. Lisac et al. [5] showed that 4-methyl imidazole plays a role as Lewis acid. When the steel was contacted by acid, the surface of the steel oxidized and released electrons. The cations of IL adsorbed the electrons on the steel surfaces. Seda et al. reported $(\mathrm{bmim})\left(\mathrm{PF}_{6}\right)$ and $(\mathrm{bmim})\left(\mathrm{BF}_{4}\right)$ as the ILs most commonly used as corrosion inhibitors [34]. However, if they are released into water, they decompose and produce hydrofluoric (HF) and phosphoric acids $\left(\mathrm{H}_{3} \mathrm{PO}_{4}\right)$ which are harmful to the environment [34]. Consequently, the oxidizing agent, water, corrosive material, and oxygen can increase the corrosion rate in the system after the corrosion inhibitor left the steel surfaces.

In this study, we developed two new ILs with high hydrophobic properties. The purpose of this study was to test the efficacies of these two ILs in preventing corrosion in carbon steel in the presence of brackish water. ILs were applied by direct injection and direct coating methods. The ILs studied include IL1(1,3-dipropyl-2-(2-propoxyphenyl)-4,5-diphenylimidazole iodide) and IL2(1,3-dibutyl-2-(2-butoxyphenyl)-4,5-diphenylimidazole iodide), whose structures were shown in Figure 1.

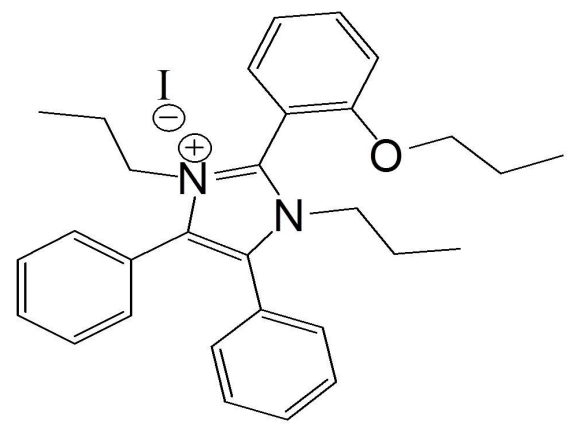

(a)

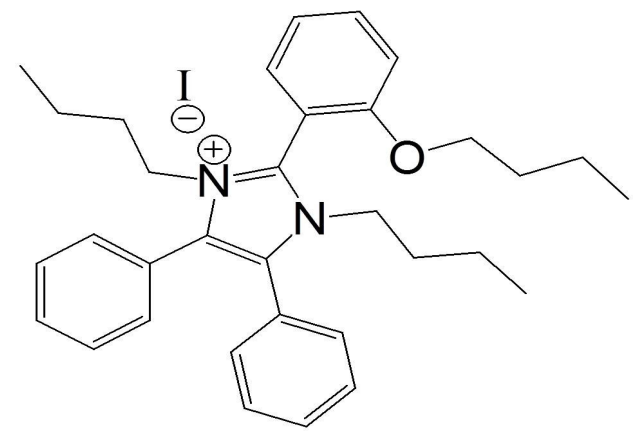

(b)

Figure 1. Chemical structures of new ionic liquids (ILs): (a) IL1; (b) IL2.

\section{Materials and Methods}

\subsection{Synthesis of ILs and Materials}

New ILs (i.e., IL1 (1,3-dipropyl-2-(2-propoxyphenyl)-4,5-diphenylimidazolium iodide) and IL2 (1,3-dibutyl-2-(2-butoxyphenyl)-4,5-diphenillimidazole iodide) were synthesized in the laboratory using 
MAOS (microwave-assisted organic synthesis) method as described by Zunita et al. [11]. An amount of $201 \mathrm{mmol}$ of 1-iodopropane was reacted with 2-(2-Hydroxyphenyl)-4,5-diphenylimidazole (67 mmol) to produce IL1 in a reactor, which was mixed with sodium hydride $(134 \mathrm{mmol})$ in tetrahydrofuran $(12 \mathrm{~mL})$. The mixture was then stirred in a magnetic stirrer tank for $20 \mathrm{~min}$. Then, the mixture was placed in the CEM (Chemistry, Electrical, Mechanical) microwave reactor set at the temperature of $190^{\circ} \mathrm{C}$ for $1.5 \mathrm{~h}$. IL2 was synthesized similarly to the procedure of the IL1 synthesis with 1-iodobutane as a butyl source in the alkylation process. The synthesis reactions were monitored by thin layer chromatography using ethyl acetate: methanol $(3: 7(v / v))$ as the eluent. The crude product was purified by a liquid-liquid extraction method using $n$-hexane $(3 \times 10 \mathrm{~mL})$. The residue was purified by column chromatography (silica gel as the stationary phase; methanol: $n$-hexane 1:9 (v/v) as the mobile phase). The ILs were dried in a vacuum oven for $4 \mathrm{~h}$. The purity of the synthesized IL1 and IL2 were analyzed by FTIR, NMR, HR-ESI-MS and elemental analysis as described by Zunita et al. [11]. The equipment used for measuring the corrosion inhibition performance of new ILs was the Potentiostat/Galvanostat PGZ 301 Radiometer. Volta Master 4 software was used to process the measurement data of the corrosion inhibition performance. The $\mathrm{NaCl}$ salts used were of reagent grade. The elemental composition of the carbon steel used in this study is shown in Table 1.

Table 1. Elemental composition of the carbon steel.

\begin{tabular}{cccccccccc}
\hline Elements & $\mathbf{C u}$ & $\mathbf{M o}$ & $\mathbf{C r}$ & $\mathbf{N i}$ & $\mathbf{M n}$ & $\mathbf{C}$ & $\mathbf{F e}$ & $\mathrm{Si}$ & $\mathbf{P}$ \\
\hline$\%-w t$ & 0.010 & 0.012 & 0.002 & 0.010 & 0.710 & 0.070 & 99.17 & 0.010 & 0.006 \\
\hline
\end{tabular}

\subsection{Corrosion Inhibition Efficiency Test of IL1 and IL2 by EIS Method}

A blank solution was prepared by providing a $1 \% \mathrm{NaCl}$ solution, and $100 \mathrm{~mL}$ of $1 \% \mathrm{NaCl}$ solution placed in a $250 \mathrm{~mL}$ beaker, which was equipped with a magnetic stirrer. Three types of electrodes were used in the experiment such as a carbon steel electrode (as a working electrode), a platinum electrode (as a supporting electrode), and a saturated calomel electrode (as a reference electrode) [11]. In the blank solution, $\mathrm{CO}_{2}$ was flowed for $30 \mathrm{~min}$ (to make sure the $\mathrm{CO}_{2}$ was saturated). Then, the Potentiostat was set in scanning the electrochemical impedance spectroscopy (EIS) method mode with a measurement frequency range of $10 \mathrm{kHz}-100 \mathrm{MHz}$ [35]. A Nyquist curve was produced first with a blank, then each of corrosion inhibitors (IL1 and IL2) was injected alternately by various concentrations of 20, 40, 60, $80,100 \mathrm{ppm}$, respectively. The addition of each IL was started from the lowest concentration to the highest without changing the blank solution. In addition, the corrosion inhibition performance test was also carried out by the coating method. IL-based corrosion inhibitors were directly applied to the carbon steel plates until they were completely covered, then allowed to dry and stick on carbon steel surfaces. Meanwhile, the corrosion inhibition performance test was carried out by the EIS method until the Nyquist curve was obtained continuously.

\subsection{Corrosion Inhibition Efficiency Test of IL1 and IL2 by Tafel Method}

A similar method used above for the EIS method was followed. The Potentiostat was run by scanning the Tafel method using the $\mathrm{E}_{\mathrm{corr}} \pm 100 \mathrm{mV}$ as the potential range [11]. The results of the electrochemical process were analyzed by the Tafel-plot method. After the measurement process was completed (marked by the release of a potential measurement curve) the Potentiostat tool was turned off and processed through one of the menus in the Potentiostat software. Processing results were obtained by Tafel method as the logarithmic curve of current versus potential. Measurements were also taken for the other samples continuously as described above.

\subsection{Statistical Analysis of Corrosion Inhibition Perfomances of IL1 and IL2}

The optimization studies of the corrosion inhibition performances of IL1 and IL2 by EIS and Tafel methods were conducted with four replicates. All the inhibition efficiency for each IL was determined 
by two application methods (i.e., direct injection and direct coating methods) with each method under four replications. The statistical analysis was conducted similar to the method used by Zunita et al. [11]. Experimental results of the corrosion inhibition performances showed standard deviations under $1 \%$.

\section{Results and Discussion}

The characterized results of the new IL1 and IL2 using FTIR, NMR, HR-ESI-MS and elemental analysis showed that IL1 and IL2 have been successfully synthesized. IL1 form is brown viscous liquids with a yield of around $92 \%$. Based on the FTIR data of IL1 showed specialty peaks $(v(\mathrm{KBr}))$ namely those of 3500, 3000, 1990, 1680, 1470, 1400, and $790 \mathrm{~cm}^{-1} .{ }^{1} \mathrm{H}-\mathrm{NMR}$ (DMSO-d $\mathrm{d}_{6}$ ) data namely $\delta$ : $7.99(\mathrm{~m}), 7.58-7.11(\mathrm{~m}), 7.04(\mathrm{~m}), 6.99-6.88(\mathrm{~m}), 4.09(\mathrm{t}, \mathrm{J}=6.6,1.4 \mathrm{~Hz}, 2 \mathrm{H}), 1.85(\mathrm{~m}), 1.00(\mathrm{t}, \mathrm{J}=7.5 \mathrm{~Hz})$, $0.44(\mathrm{t}, \mathrm{J}=30.0,7.5 \mathrm{~Hz})$ and ${ }^{13} \mathrm{C}-\mathrm{NMR}\left(\mathrm{DMSO}^{\mathrm{d}} \mathrm{d}_{6}\right)$ namely $\delta: 10.4,10.7,11.9,22.6,25.9,23.5,68,9,51.5$, and $49.0 \mathrm{ppm}$. The HR-ESI-MS $(\mathrm{M}+\mathrm{H})$ analysis showed $\mathrm{m} / \mathrm{z} 440.28$. The elemental analysis data of IL1 showed the following compositions C: $64.00 \%, \mathrm{H}: 6.21 \%$, and N: $4.96 \%$. Meanwhile, the IL2 form was brown viscous liquid with a yield of around $91 \%$. The FTIR data of IL2 showed specialty peaks $(v(\mathrm{KBr}))$ namely those of $3400,2870,1990,1650,1420,700 \mathrm{~cm}^{-1}$. In addition, also supported by ${ }^{1} \mathrm{H}-\mathrm{NMR}\left(\right.$ DMSO-d $\left._{6}\right)$, the ${ }^{1} \mathrm{H}$ NMR date $\left(\right.$ DMSO-d $\left._{6}\right): 8:$ 7.55-7.45 (m), $4.14(\mathrm{t}, \mathrm{J}=6.2 \mathrm{~Hz}), 3.99-3.87(\mathrm{~m})$, 1.54-1.46 (m), $1.32-1.24(\mathrm{~m}), 0.97-0.83(\mathrm{~m}), 0.51-0.43(\mathrm{~m})$ and ${ }^{13} \mathrm{C}$ NMR (DMSO-d $\mathrm{d}_{6}$ ) namely $8: 14.1$, $13.8,13.9,31.8,20.7,20.5,31.9,32.9,33.8,68.7,49.3$, and 46.5 ppm. HR-ESI-MS (M+H) analysis showed $\mathrm{m} / \mathrm{z}:$ 482.32. The elemental analysis data showed that the compositions of IL2 are C: 65.11, H: 6.75, and N: 4.62. IL1 and IL2 were applied as corrosion inhibitors on carbon steel surfaces and tested by the EIS method and the Tafel method to demonstrate corrosion inhibition performance. The corrosion condition was designed to match the corrosion condition of the carbon steel pipes in a brackish water model $(1 \% \mathrm{NaCl})$. All experiments were carried out at various temperatures and concentrations.

\subsection{Results of Inhibition Efficiency Test of IL1 and IL2 as Corrosion Inhibitor by the EIS Method}

Percent inhibition efficiency (IE\%) of IL1 and IL2 were calculated by Equation (1) as per Popova et al. [36]:

$$
\mathrm{IE} \%=\frac{\mathrm{R}_{\text {inhibitor }}-\mathrm{R}_{\text {blank }}}{\mathrm{R}_{\text {blank }}} \times 100 \%
$$

where $R_{\text {inhibitor }}$ is the resistance after the addition of corrosion inhibitor, whereas $R_{\text {blank }}$ is the resistance before the addition of the corrosion inhibitor. In this study, the concentration range of the new ILs used was 20-120 ppm to get the optimum concentration for corrosion inhibition in brackish water. The optimum concentration of the IL1 and IL2 precursors, which have corrosion inhibition concentration potential, was reported previously to be in the range $80-100 \mathrm{ppm}$ [11]. The resistance value after the addition of the inhibitor will be higher than the resistance value without the addition of the corrosion inhibitor as reported earlier by others $[9,29]$. This shows that the resistance on the electric surface will be much higher if the carbon steel surface has been coated by the corrosion inhibitor. Consequently, the semicircular diameter of the Nyquist $Z$ curve will enlarge after the addition of corrosion inhibitors [35]. The IE\% of IL2 is higher than IL1 due to the presence of three butyl chains in IL2 which increase hydrophobicity and also decrease the interaction between the steel surface and the corrosion agent as reported by Zunita et al. [11] and also the longer alkyl chains can increase the inhibition efficiency in $1 \% \mathrm{NaCl}$. Based on Figure 2, the $\mathrm{Zr}$ to $-\mathrm{Zi}$ data with the addition of $80 \mathrm{ppm}$ IL1 and $60 \mathrm{ppm}$ IL2 showed the effect of the decreasing corrosion rate. The increased corrosion resistance in the system was indicated by the larger diameter of the semicircular curve. However, when the IL1 concentration was increased to $100 \mathrm{ppm}$ and IL2 to $120 \mathrm{ppm}$, the results showed a slight decrease in the corrosion inhibition. This validated that the optimum range for corrosion inhibition for IL1 was around 80-100 ppm and for IL2, it was around 60-100 ppm, with the best corrosion inhibition concentration at $80 \mathrm{ppm}$ for IL1 and $100 \mathrm{ppm}$ for IL2. 


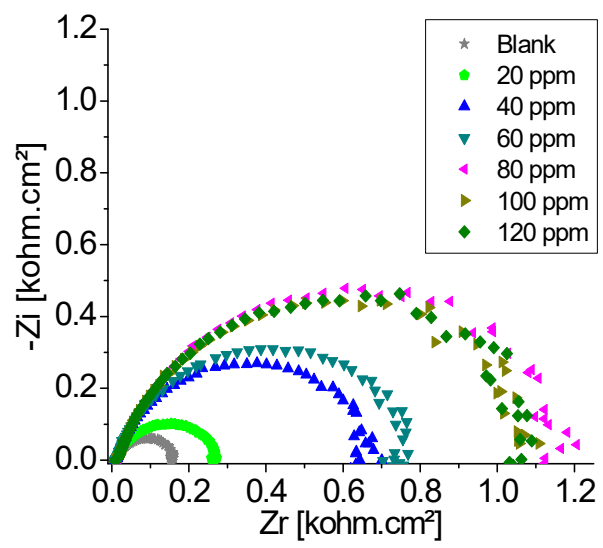

(a)

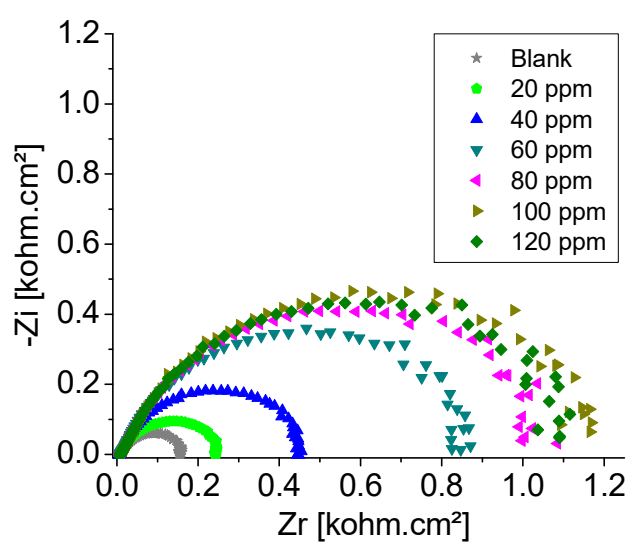

(b)

Figure 2. Nyquist $Z$ curves of (a) IL1 and (b) IL2 at $25^{\circ} \mathrm{C}$.

The results of the corrosion inhibition performance test using the EIS method showed that IL1 and IL2 have potential as corrosion inhibitors. The percent inhibition efficiency (IE\%) of each of IL was higher than $80 \%$, which is shown in Figure 3.
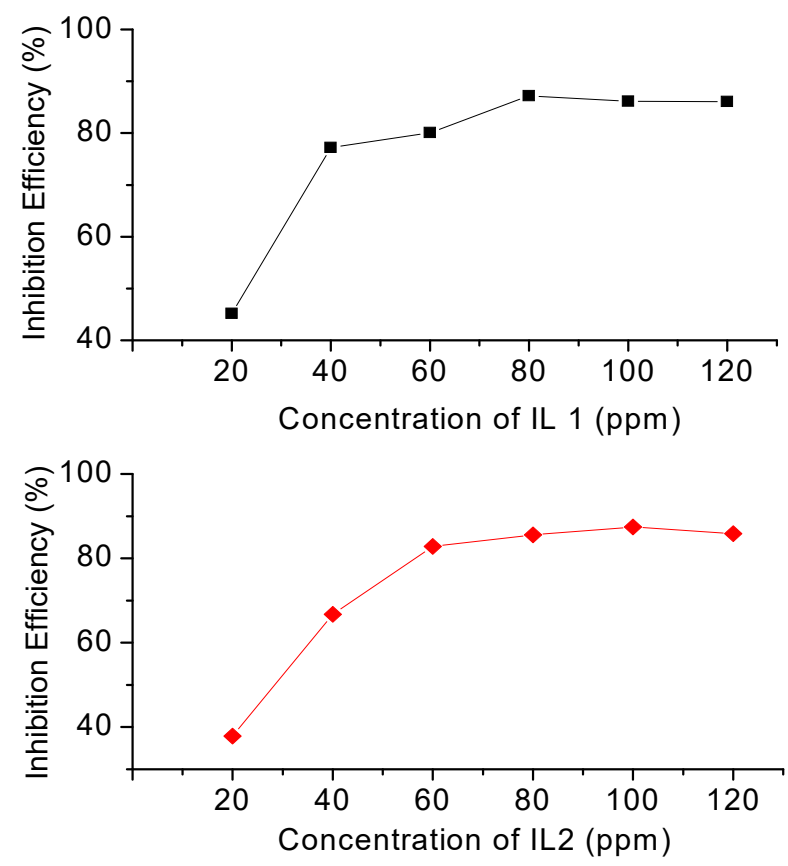

Figure 3. Inhibition efficiency of ILs at various concentrations at a temperature of $25^{\circ} \mathrm{C}$.

The above results showed that new ILs have potency as a corrosion inhibitor, but the IE\% of each IL was still only $80 \%$. Therefore, the application method of IL-based corrosion inhibitors was modified to increase the IE\% value with direct injection method by the direct coating of ILs on carbon steel surfaces. Two drops each of IL were weighed and the weight was noted for applying the direct coating method on the carbon steel surface and the coated carbon steel coupon was dried in the open air for $1 \mathrm{~h}$. The coated carbon steel was added to the system containing $1 \% \mathrm{NaCl}$ solution. The test was carried out at various temperatures ranging from $25^{\circ} \mathrm{C}$ to $55^{\circ} \mathrm{C}$ with the increase of $10^{\circ} \mathrm{C}$. After the measurements were completed with the low temperature range, the carbon steel coupon was replaced with the newly coated carbon steel coupon and the measurement was carried out at the higher temperatures. Since the ILs are hydrophobic, all ILs were not dissolved in water during the measurement. The IE\% data of the coated carbon steels are shown in Table 2. 
Table 2. Percent inhibition efficiency (IE\%) of the carbon steels directly coated with IL1 and IL2.

\begin{tabular}{ccc}
\hline \multirow{2}{*}{$\begin{array}{c}\text { Temperature } \\
\left({ }^{\circ} \mathbf{C}\right)\end{array}$} & \multicolumn{2}{c}{ IE\% } \\
\cline { 2 - 3 } & 20 ppm of IL1 & 18 ppm of IL2 \\
\hline 25 & $99.3 \pm 0.5$ & $99.3 \pm 1.0$ \\
35 & $32.5 \pm 0.4$ & $61.9 \pm 0.6$ \\
45 & $24.0 \pm 0.3$ & $50.6 \pm 1.0$ \\
55 & $12.5 \pm 0.5$ & $33.6 \pm 1.0$ \\
\hline
\end{tabular}

Data in Table 2 show that the IE\% of IL1 and IL2 were increased by using the direct coating method. The IE\% values of IL1 and IL2 at $25^{\circ} \mathrm{C}$ were $99.3 \%$ and $99.2 \%$. These data showed that the role of the long alkyl chain (propyl and butyl) in the two ILs increased their hydrophobicity properties $[8,21]$. Thus, the carbon steel surface was protected from polar and corrosive environments like water and $1 \%$ $\mathrm{NaCl}$, which can increase the corrosion rate.

In this study, the adsorption mechanisms of a new IL-based corrosion inhibitor on carbon steel surfaces were also determined. The adsorption mechanisms on carbon steel surfaces follow the Langmuir isotherm model and the Temkin isotherm model due to the ILs interaction with carbon steel surfaces assume the gas phase. Initially corrosion inhibitors were made in the gas phase in order to form a thin layer on the surface of carbon steel [37]. The Langmuir isotherm model was developed for observing the mechanism of the absorption and desorption of the molecules on the surface of the adsorbate with zero accumulation rate, which can be used to quantify the capacity of various concentrations of adsorbents. Meanwhile, the Temkin isotherm model was developed to observe the interaction between adsorbents and adsorbates at extremely large and low concentration values, and this model assumes that adsorption heat as a function of temperature. Resistance values of each IL were measured by the EIS method at the best condition (temperature $25^{\circ} \mathrm{C}$ ). The resistance on the carbon steel surface increased after the addition of ILs indicates that the corrosion reaction was not occurring, whereas, in the control, corrosion reaction took place quickly and spontaneously. The spontaneity or non-spontaneity of corrosion reaction on the carbon steel surface was determined by the corrosion inhibition performance test. The determination of Langmuir adsorption mechanism of IL1 and IL2 were calculated by using Equations (2) and (3) and generated the data of $\theta, C / \theta$, and $\ln C$. Below is Equation (2) for the Langmuir adsorption isotherm [38]:

$$
\theta=\frac{b C_{\text {inh }}}{1+b C_{\text {inh }}}
$$

$\theta=$ degree of surface cover;

$\mathrm{b}=$ adsorption coefficient;

$\mathrm{C}_{\text {inh }}=$ inhibitor concentration.

The other form of the equation above is:

$$
\frac{\mathrm{C}}{\theta}=\mathrm{C}+\frac{1}{\mathrm{~b}}
$$

The intercept section (b) equal to the $\mathrm{K}_{\mathrm{ads}}$ value (the adsorption process constant) procured by using the relationship $\mathrm{Y}=\mathrm{mX}+\mathrm{C}$, according to the following equations:

$$
\begin{gathered}
\mathrm{b}=\mathrm{K}_{\mathrm{ads}}=\frac{\theta}{\mathrm{C}(1-\theta)} \\
\Delta \mathrm{G}_{\mathrm{ads}}=-\mathrm{RT} \ln \left(55,55 \mathrm{~K}_{\mathrm{ads}}\right)
\end{gathered}
$$

Based on the two equations above (Equations (4) and (5)), the values of the free energy adsorption $\left(\Delta \mathrm{G}_{\mathrm{ads}}, \mathrm{kJ} / \mathrm{mol}\right)$ of IL1 and IL2 can be determined. The $\Delta \mathrm{G}_{\mathrm{ads}}$ of each IL is shown in Table 3. 
Table 3. Results of the adsorption mechanism determination of IL1 and IL2 following the Langmuir isotherm model.

\begin{tabular}{ccccc}
\hline IL & Gradient (m) & Intercept Value (C) & $\mathbf{K}_{\text {ads }}\left(\mathbf{M}^{-\mathbf{1}}\right)$ & $\Delta \mathbf{G}_{\text {ads }}(\mathbf{k J} / \mathbf{m o l})$ \\
\hline 1 & $2.00 \times 10^{-6}$ & $4.00 \times 10^{-5}$ & $2.50 \times 10^{5}$ & -35.04 \\
2 & $8.83 \times 10^{-1}$ & $6.00 \times 10^{-5}$ & $1.67 \times 10^{4}$ & -34.04 \\
\hline
\end{tabular}

In addition, the determination of the adsorption mechanism of IL1 and IL2 was also carried out by the Temkin adsorption isotherm. The calculation of the Temkin isotherm adsorption mechanism was carried out using Equation (6) [39]. The calculated results of the ILs are described in the linear graph as shown in Figure 4:

$$
\theta=\frac{\mathrm{RT}}{\mathrm{b}} \ln \left(\mathrm{C}_{\mathrm{inh}}\right)
$$

At the same step, the free energy of the adsorption values $\left(\Delta \mathrm{G}_{\mathrm{ads}}, \mathrm{kJ} / \mathrm{mol}\right)$ of IL1 and IL2 were also determined by using the Temkin isotherm model as shown in Table 4 . Figure 4 shows the results of the data described in the linear graph of Langmuir and Temkin adsorption isotherms.

Table 4. Results of the adsorption mechanism determination of IL1 and IL2 following the Temkin isotherm model.

\begin{tabular}{ccccc}
\hline $\mathbf{I L}$ & Gradient $(\mathbf{m})$ & Intercept Value (C) & $\mathbf{K}_{\text {ads }}\left(\mathbf{M}^{-\mathbf{1}}\right)$ & $\boldsymbol{\Delta G}_{\mathbf{a d s}}(\mathbf{k J} / \mathbf{m o l})$ \\
\hline 1 & 0.222 & 2.754 & $3.63 \times 10^{-1}$ & -7.44 \\
2 & 0.278 & 3.231 & $3.10 \times 10^{-1}$ & -7.05 \\
\hline
\end{tabular}

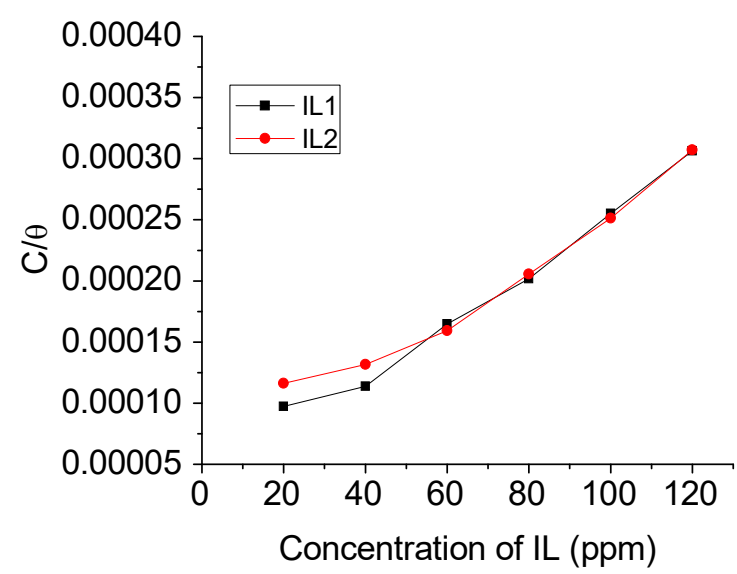

(a)

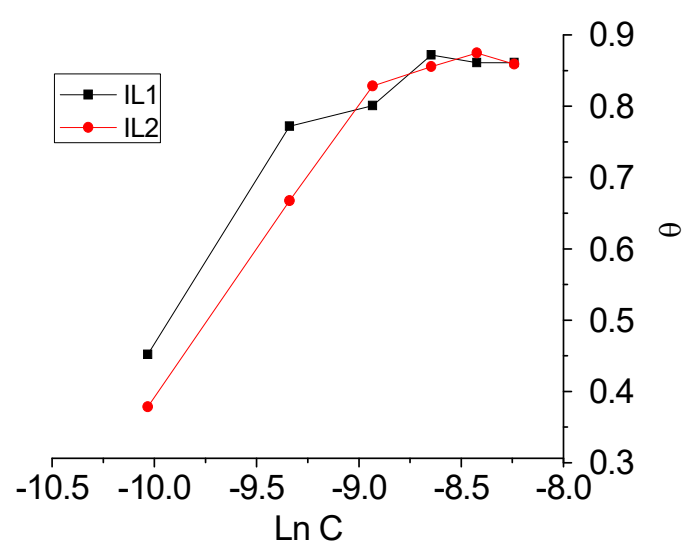

(b)

Figure 4. Langmuir adsorption isotherm (a) and Temkin adsorption isotherm (b) for IL1 and IL2.

Figure 4 shows that IL1 and IL2 showed a better fit in the Langmuir adsorption model than the Temkin adsorption model. IL1 and IL2 have big steric hindrance and high hydrophobicity properties and during the corrosion reaction on carbon steel surfaces, the bulk cations of IL1 and IL2 can easily and directly bind to electrons on the metal surfaces. In addition, the $\mathrm{R}^{2}$ values of IL1 and IL2 for each curve in Figure 4a showed that the adsorption mechanisms of new ILs follow the Langmuir adsorption isotherm with the $\mathrm{R}^{2}$ value close to 1 for IL1 and IL2 (i.e., 0.983 and 0.965 , respectively) and it is almost linear. The $R^{2}$ values of IL1 and IL2 following the Temkin adsorption mechanism were far from linear form as shown in Figure $4 \mathrm{~b}$. Table 3 also showed that IL1 and IL2 followed the Langmuir adsorption model with $\Delta \mathrm{G}_{\text {ads }}$ of $-35.04 \mathrm{~kJ} / \mathrm{mol}$ for IL1 and $-34.04 \mathrm{~kJ} / \mathrm{mol}$ for IL2. In general, these $\Delta \mathrm{G}_{\text {ads }}$ values show that the adsorption of IL1 and IL2 have occurred on carbon steel surface due to semi-chemical adsorption and or physical adsorption as indicated by their $\Delta \mathrm{G}_{\mathrm{ads}}$, which is higher than $-30 \mathrm{~kJ} / \mathrm{mol}$ and lower than $-40 \mathrm{~kJ} / \mathrm{mol}[40-42]$. 
Kinetics data (activation energy) of IL1 and IL2 were also evaluated by the EIS method following Equation (7) $[11,43]$. The activation energy $\left(E_{a}\right)$ shows the lowest energy needed to carry out the corrosion reaction $[13,21]$. The activation energy $\left(E_{a}\right)$ for IL1 and IL2 for the various concentrations at various temperatures is given in Figure 5:

$$
\ln \left(\mathrm{I}_{\mathrm{corr}}\right)=\ln \mathrm{A}-\frac{\mathrm{E}_{\mathrm{a}}}{\mathrm{RT}}
$$

where $\mathrm{A}$ is an empirically Arrhenius constant, $\mathrm{I}_{\text {corr }}$ is the current density of the corrosion rate of the system, $\mathrm{E}_{\mathrm{a}}$ is the activation energy of the corrosion process $(\mathrm{kJ} / \mathrm{mol}), \mathrm{R}$ is the ideal gas constant $\left(8.314 \mathrm{~J} \cdot \mathrm{mol}^{-1} \mathrm{~K}^{-1}\right)$, and $\mathrm{T}$ is the temperature $(\mathrm{K})$. The linear line the equations obtained illustrates the relationship of $Y=m X+C$ which is equivalent to $\ln \left(I_{c o r r}\right)=\left[-E_{a} / R\right](1 / T)+\ln A$. Based on Equation (7), the graphs were made from the data $\ln \left(\mathrm{I}_{\mathrm{corr}}\right)$ versus $1 / \mathrm{T}$ (multiplied by 1000) to get a linear relationship as shown in Figure 5. The activation energy data of the corrosion process subsequent to the addition of IL1 and IL2 are summarized in Table 5.

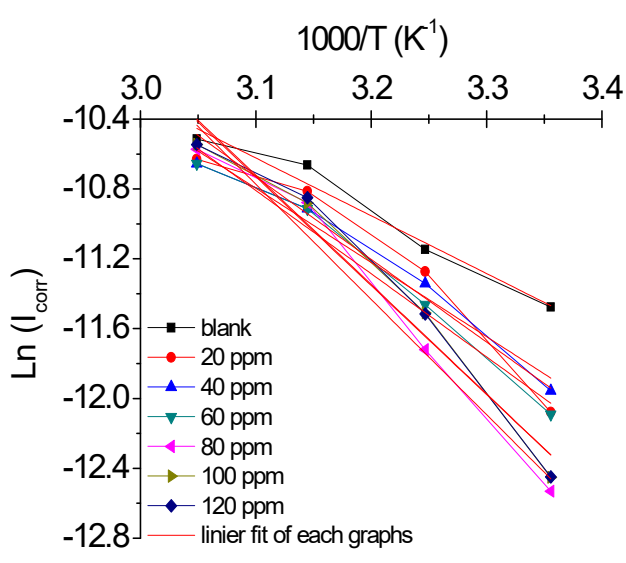

(a)

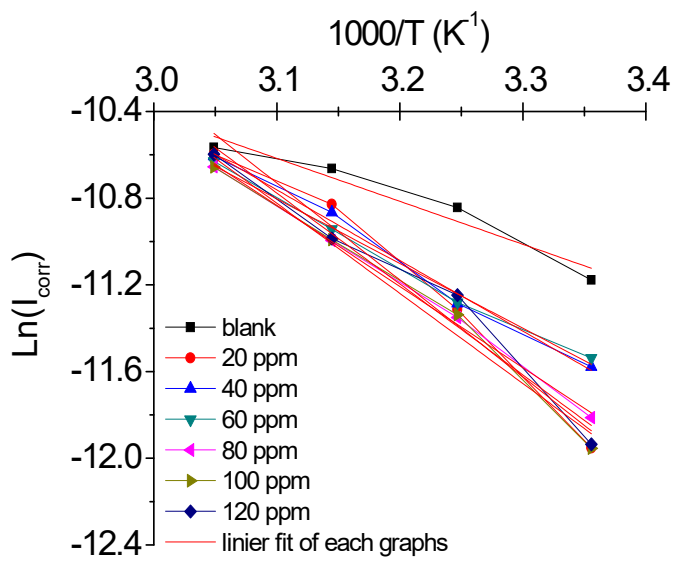

(b)

Figure 5. Graphs of the activation energy $\left(E_{a}\right)$ determination $\left(\operatorname{Ln}\left(\mathrm{I}_{\mathrm{corr}}\right)\right.$ towards the $\left.1000 / \mathrm{T}\right)$ subsequent to the addition of IL1 (a) and IL2 (b) in various concentrations.

Table 5. $\mathrm{E}_{\mathrm{a}}$ corrosion reaction subsequent to the addition of IL1 and IL2 to $1 \% \mathrm{NaCl}$.

\begin{tabular}{cccccccc}
\hline & \multicolumn{6}{c}{$\mathbf{E}_{\mathbf{a}}(\mathbf{k J} / \mathbf{m o l})$} \\
\cline { 2 - 8 } IL & $\begin{array}{c}\text { Control } \\
(\mathbf{1 \% ~ N a C l )})\end{array}$ & $\mathbf{2 0}$ & $\mathbf{4 0}$ & $\mathbf{6 0}$ & $\mathbf{8 0}$ & $\mathbf{1 0 0}$ & $\mathbf{1 2 0}$ \\
\hline 1 & 27.5 & 39.3 & 60.2 & 64.5 & 79.7 & 76.7 & 77.0 \\
2 & 23.9 & 37.2 & 52.0 & 67.1 & 71.0 & 74.4 & 72.2 \\
\hline
\end{tabular}

Table 5 shows that the corrosion rates in the system decreased after the addition of new ILs. The $E_{a}$ values for the control without IL were relatively low, namely 27.5 and $23.9 \mathrm{~kJ} / \mathrm{mol}$. These data showed that the corrosion reaction occurred without ILs in the system. After the addition of new ILs, the inhibition of corrosion happened quickly, with $\mathrm{E}_{\mathrm{a}}$ corrosion reactions increased with the increase in the concentration of ILs. The efficient concentration of IL1 that can inhibit the corrosion rate was $80 \mathrm{ppm}$ with the $\mathrm{E}_{\mathrm{a}}$ value around $79.7 \mathrm{~kJ} / \mathrm{mol}$. While the efficient concentration of IL2 to inhibit the corrosion rate was $100 \mathrm{ppm}$, the $\mathrm{E}_{\mathrm{a}}$ value was around $74.4 \mathrm{~kJ} / \mathrm{mol}$. The results showed that the optimum concentrations to apply for IL1 and IL2 by using the direct injection method are 80 and $100 \mathrm{ppm}$, respectively. The direct coating method of IL1 and IL2 achieved corrosion inhibition at a significantly lower concentration of $20 \mathrm{ppm}$ and $18 \mathrm{ppm}$, respectively. IL2 has better corrosion inhibition performance than IL1 due to higher hydrophobicity. The effect of free electrons from the oxygen 
atom of the hydroxyl group helped to inhibit the oxidation process on carbon steel surfaces $[40,41]$. Three butyl chains of IL2 increased corrosion inhibition performance.

The thermodynamic parameters of the corrosion inhibition process were also investigated. The thermodynamic parameters were very important to show whether the corrosion inhibition reaction in the system was occurring. Thermodynamic parameters can be obtained from Equation (8) below [42].

$$
\ln \frac{\mathrm{I}_{\text {corr }}}{\mathrm{T}}=\ln \frac{\mathrm{R}}{\mathrm{Nh}}+\frac{\Delta \mathrm{S}^{*}}{\mathrm{R}}-\frac{\Delta \mathrm{H}^{*}}{\mathrm{RT}}
$$

where $\mathrm{R}$ is the constant of ideal gas $\left(\mathrm{J} \cdot \mathrm{mol}^{-1} \mathrm{~K}^{-1}\right), \mathrm{N}$ is the Avogadro number $\left(\mathrm{mol}^{-1}\right), \mathrm{h}$ is the Plank constant $\left(6.63 \times 10^{-34} \mathrm{~J} \cdot \mathrm{s}^{-1}\right), \Delta \mathrm{S}^{*}$ is the change of entropy of corrosion inhibition process $\left(\mathrm{J} \cdot \mathrm{mol}^{-1}\right)$, $\Delta \mathrm{H}^{*}$ is the change of enthalpy of corrosion inhibition process $\left(\mathrm{J} \cdot \mathrm{mol}^{-1}\right), \mathrm{T}$ is the temperature operation $(\mathrm{K})$, and $\mathrm{I}_{\text {corr }}$ is the current of corrosion (Ampere) which can be obtained from Equation (9):

$$
\mathrm{I}_{\text {corr }}=\frac{\mathrm{K}}{\mathrm{R}_{\mathrm{p}} \mathrm{L}}
$$

where $\mathrm{K}$ is an empirical constant which has a value of $0.02 \mathrm{~V}, \mathrm{R}_{\mathrm{p}}$ is the value of resistance in the system $\left(\mathrm{ohm} \cdot \mathrm{cm}^{2}\right)$, and $\mathrm{L}$ is the diameter of the metal used during measurement $(\mathrm{mm})$. The analysis of $\ln \left(\mathrm{I}_{\mathrm{corr}} / \mathrm{T}\right)$ to $1 / \mathrm{T}$ was carried out by the following linear equation $\mathrm{Y}=\mathrm{mX}+\mathrm{C}$ corresponding to $\ln \left(\mathrm{I}_{\mathrm{corr}} / \mathrm{T}\right)=\left[-\Delta \mathrm{H}^{*} / \mathrm{R}\right](1 / \mathrm{T})+\left[\ln (\mathrm{R} / \mathrm{nh})+\Delta \mathrm{S}^{*} / \mathrm{R}\right]$. The interpretation and analysis of $\ln \left(\mathrm{I}_{\text {corr }} / \mathrm{T}\right)$ to $1 / \mathrm{T}$ graphs of IL1 and IL2 as shown in Figure 6a,b were based on the calculated data using Equation (8). The free energy values of IL1 and IL2 calculated by Equation (10) are presented in Figure $6 c, d$. The thermodynamic parameters of IL1 and IL2 as corrosion inhibitors on carbon steel surface in 1\% $\mathrm{NaCl}$ are summarized in Table 6.

$$
\Delta \mathrm{G}^{*}=\Delta \mathrm{H}^{*}-\mathrm{T} \Delta \mathrm{S}^{*}
$$

Table 6. Thermodynamic parameters of IL1 and IL2 as corrosion inhibitors on carbon steel surface in $1 \% \mathrm{NaCl}$.

\begin{tabular}{ccccc}
\hline \multirow{2}{*}{ Concentration of IL (ppm) } & \multicolumn{2}{c}{ IL1 } & \multicolumn{2}{c}{ IL2 } \\
\cline { 2 - 5 } & $\mathbf{\Delta \mathbf { H } ^ { * } \mathbf { ( k J } / \mathbf { m o l } )}$ & $\left.\boldsymbol{\Delta} \mathbf{S}^{*} \mathbf{( J / m o l}\right)$ & $\boldsymbol{\Delta} \mathbf{H}^{*}(\mathbf{k J} / \mathbf{m o l})$ & $\left.\boldsymbol{\Delta} \mathbf{S}^{*} \mathbf{J} / \mathbf{m o l}\right)$ \\
\hline 0 & 27.5 & -248.0 & 23.9 & -258.8 \\
20 & 39.3 & -212.1 & 37.2 & -218.9 \\
40 & 60.2 & -147.6 & 52.0 & -172.9 \\
60 & 64.5 & -134.5 & 57.1 & -125.9 \\
80 & 79.7 & -87.0 & 71.0 & -114.4 \\
100 & 76.7 & -95.9 & 74.4 & -103.8 \\
120 & 77.0 & -95.0 & 72.2 & -110.2 \\
\hline
\end{tabular}

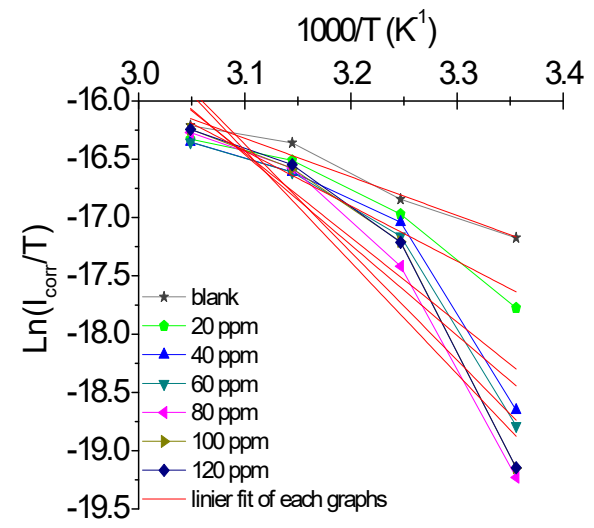

(a)

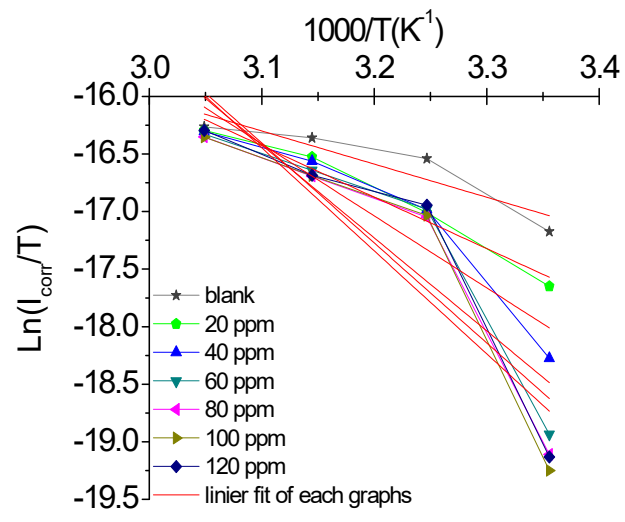

(b)

Figure 6. Cont. 


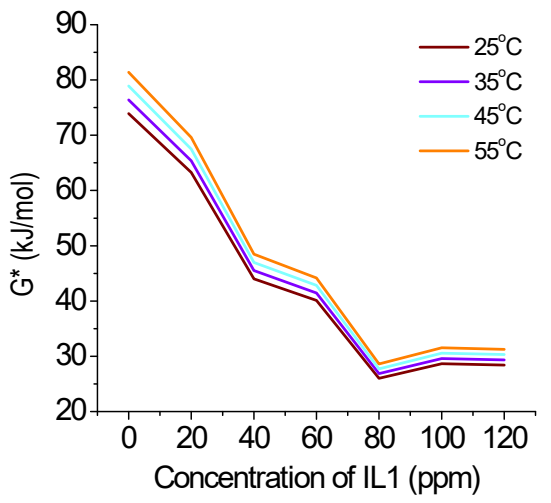

(c)

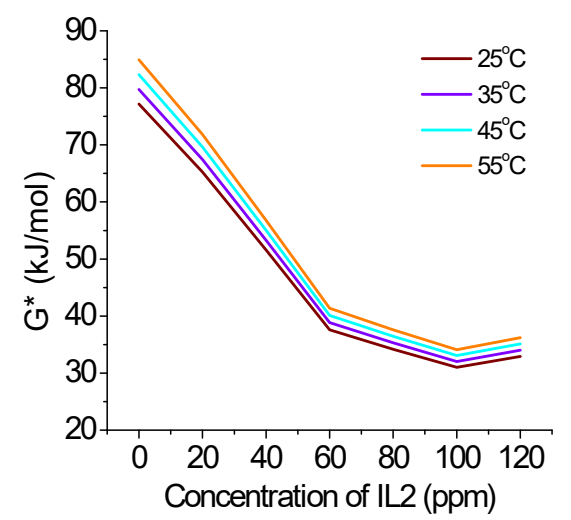

(d)

Figure 6. Graphs of the correlation between $\ln \left(\mathrm{I}_{\mathrm{corr}} / \mathrm{T}\right)$ towards $1000 / \mathrm{T}$ in the corrosion system after the addition of IL1 (a) and IL2 (b); (c,d) represent the free energy values $\Delta G^{*}$ of the corrosion system after the addition of IL1 and IL2 at various temperatures, respectively.

The results in Table 6 show that IL1 and IL2 thermodynamically inhibit the corrosion rate in the brackish water system, which was indicated by the increase in the $\Delta \mathrm{H}^{*}$ and $\Delta \mathrm{S}^{*}$ values. In the blank the required energy for the corrosion reaction $\left(\Delta \mathrm{H}^{*}\right)$ was very low, such as the $27.5 \mathrm{~kJ} / \mathrm{mol}$ and $\Delta \mathrm{S}^{*}$ value was $-248.0 \mathrm{~J} / \mathrm{mol}$. These data show that the corrosion in the brackish water system occurred quickly due to the significant increase in $\mathrm{I}_{\text {corr }} / \mathrm{T}$ at a low temperature $\left(25^{\circ} \mathrm{C}\right)$ as shown in Figure $6 \mathrm{a}, \mathrm{b}$. A correlation between the $\mathrm{I}_{\mathrm{corr}} / \mathrm{T}$ and $\ln \mathrm{I}$ corr $/ \mathrm{T}$ shows that it is indirectly proportional. With the increase in 1000/T values, the $\ln \mathrm{I}_{\text {corr }} / \mathrm{T}$ values decreased. The results also showed that the corrosion reaction occurs easily at higher temperatures. The data of $\ln \left(\mathrm{I}_{\text {corr }} / \mathrm{T}\right)$ versus $1 / \mathrm{T}$ were also supported by the $\Delta \mathrm{G}^{*}$ values without the addition of ILs which are very high (higher than $70 \mathrm{~kJ} / \mathrm{mol}$ ) as presented in Figure $6 \mathrm{c}, \mathrm{d}$, leading to rapid corrosion in the system. To inhibit the corrosion reaction in the system, the $\mathrm{I}_{\text {corr }}$ value should be low resulting in the slow oxidation of carbon steel $[13,20,21]$. The addition of IL1 and IL2 increased the hydrophobic properties of the system and inhibited the corrosion reaction between the carbon steel and corrosion agents.

These results clearly show that corrosion reactions in the system are inhibited by ILs because the addition of ILs decreases the $\Delta \mathrm{G}^{*}$ values [42]. The maximum corrosion inhibition was achieved with $80 \mathrm{ppm}$ of IL1 and $100 \mathrm{ppm}$ of IL2 at the temperature of $25^{\circ} \mathrm{C}$ as shown in Figures $6 \mathrm{c}$ and $6 \mathrm{~d}$, respectively. The $\Delta G^{*}$ decreased after the addition of IL1 and IL2 to $20 \mathrm{~kJ} / \mathrm{mol}$ and $30 \mathrm{~kJ} / \mathrm{mol}$, respectively. The corrosion reaction energy requirement can be decreased up to $40-50 \mathrm{~kJ} / \mathrm{mol}$ after the addition of IL1 and IL2. When the IL concentration was increased higher than $80 \mathrm{ppm}$, the performance of IL1 decreased. This is because IL1 tended to saturate and agglomerate at a concentration above $80 \mathrm{ppm}$. The same phenomenon happened for IL2 when the concentration was increased to higher than $100 \mathrm{ppm}$. Therefore, the optimum concentration for IL1 is $80 \mathrm{ppm}$ and the optimum concentration for IL2 was $100 \mathrm{ppm}$ at room temperature $\left(25^{\circ} \mathrm{C}\right)$. The experimental results by the EIS method show that IL1 and IL2 have good corrosion inhibitor activities on carbon steel surfaces under the brackish water condition. These data were validated by the Tafel method as described below.

\subsection{Results of the Corrosion Inhibition Efficiency Test of IL1 and IL2 by the Tafel Method}

The corrosion inhibition efficiency test by using the Tafel method showed that IL1 and IL2 protect carbon steel surfaces as well as anodic protection as shown in the Tafel extrapolation curve in Figure 7. 


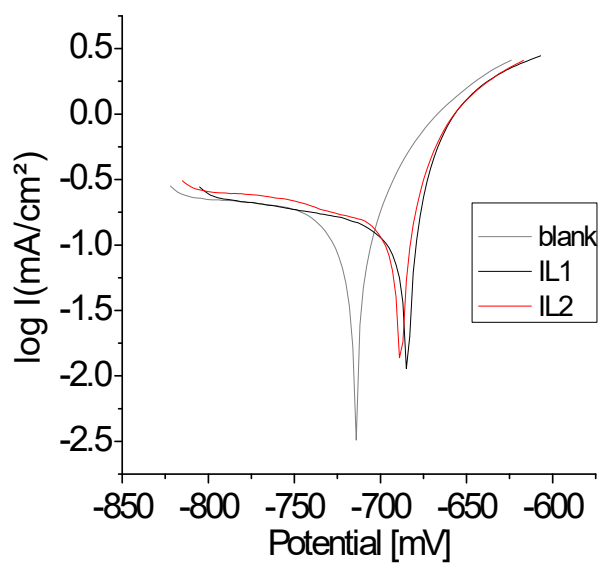

(a)

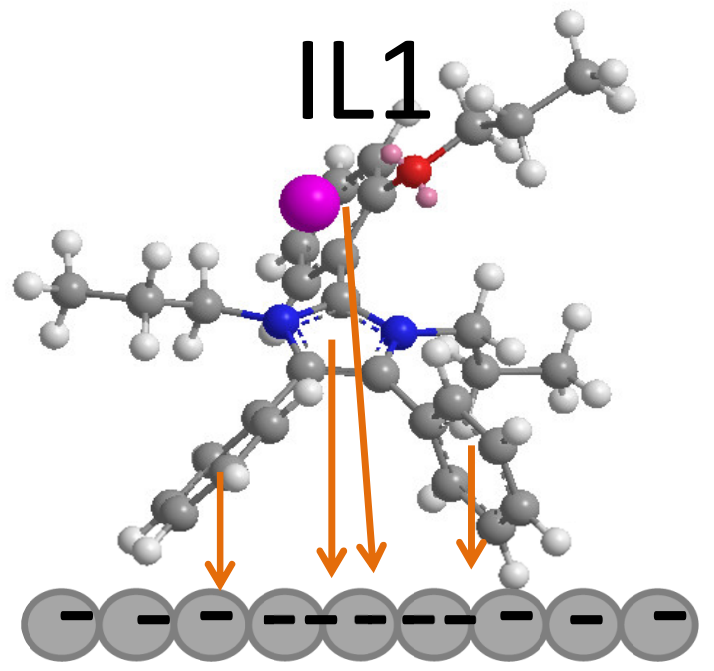

(b)

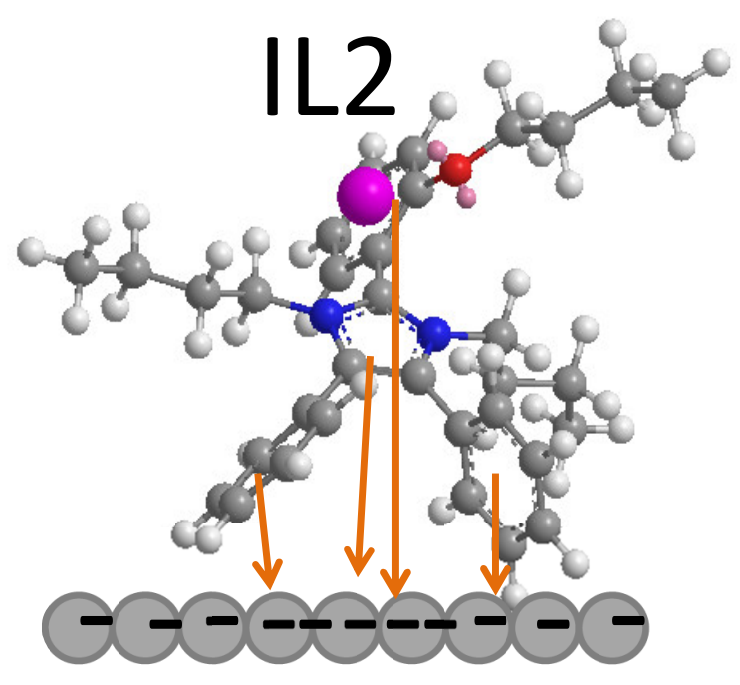

(c)

Figure 7. (a) Extrapolation Tafel curve of IL1 and IL2 and (b) the 3D visualization illustration of the interaction between IL1 and (c) IL2 on the carbon steel surface (note: the red ball reflects the oxygen atom, the blue ball reflects the nitrogen atom, the purple ball reflects the iodine atom, the grey ball reflects the carbon atom, and the white ball reflects the hydrogen atom).

As a general demonstration of IL1 and IL2 in protecting the metal surfaces, the 3D visualization models of the interaction of each IL1 and IL2 on carbon steel surfaces are shown in Figure 7. This shows that the presence of free electrons on the $\mathrm{O}$ atom and the resonance of electrons from the aromatic ring of ILs contribute to interact with the carbon steel surface. In addition, the cations of imidazole salts can electrostatically interact with electron clouds on the carbon steel surface, resulting in a decrease in the oxidation rate of carbon steel.

The results of the corrosion inhibition efficiency test showed that IL1 and IL2 have potency as corrosion inhibitors using the direct injection method and direct coating method in $1 \% \mathrm{NaCl}$ solution. Since IL1 and IL2 have larger ionic polarity, the capability to protect carbon steel surface by direct coating was better than the direct injection method. 
The presence of water and other polar compounds in a corrosion system can promote the carbon steel oxidation rate. Hence, water and other polar compounds need to be removed from the system (on the carbon steel surface). The position of propyl and butyl groups in IL1 and IL2 structures were designed to make a distant orientation between the carbon steel surface and corrosion agents. Under certain conditions, the addition of hydrophobic groups can improve corrosion inhibition performance through the process of preventing interactions between water molecules and electrolyte solutions from carbon steel surfaces $[8,15,40,41]$.

\section{Conclusions}

The corrosion inhibition efficiency test shows that IL1 and IL2 have potency as corrosion inhibitors on carbon steel surfaces in a brackish water model system ( $1 \% \mathrm{NaCl}$ solution). The two application methods that can be used to apply new ILs as corrosion inhibitors are the direct injection and the direct coating methods. The optimum conditions of corrosion inhibition by the addition of IL1 and IL2 using the direct injection method were $80 \mathrm{ppm}$ and $100 \mathrm{ppm}$ at a temperature of $25^{\circ} \mathrm{C}$, respectively. To increase the performances of IL1 and IL2 for corrosion inhibition in brackish water, the direct coating method is recommended. The $\Delta \mathrm{G}_{\text {ads }}$ values of IL1 and IL2 at the optimum conditions were -35.04 and $-34.04 \mathrm{~kJ} / \mathrm{mol}$, respectively.

Author Contributions: Conceptualization, M.Z., D.W., B. and B.B.; methodology, M.Z.; software, M.Z.; validation, M.Z. and B.B.; formal analysis, M.Z. and D.W.; investigation, M.Z.; resources, M.Z.; data curation, M.Z.; writing-original draft preparation, M.Z.; writing—review and editing, M.Z., D.W., IG.W. and R.B.; visualization, M.Z., D.W., IG.W. and R.B.; supervision, D.W., B. and B.B.; project administration, M.Z. and D.W.; funding acquisition, M.Z., D.W., B. and B.B. All authors have read and agreed to the published version of the manuscript.

Funding: This research received no external funding.

Acknowledgments: The authors gratefully acknowledge financial support from IMHERE-FMIPA Institut Teknologi Bandung.

Conflicts of Interest: The authors declare no conflict of interest.

\section{References}

1. Oguzie, E.; Li, Y.; Wang, F. Corrosion inhibition and adsorption behavior of methionine on mild steel in sulfuric acid and synergistic effect of iodide ion. J. Colloid Interface Sci. 2007, 310, 90-98. [CrossRef] [PubMed]

2. Makertihartha, I.; Dharmawijaya, P.; Zunita, M.; Wenten, I. Post combustion $\mathrm{CO}_{2}$ capture using zeolite membrane. In AIP Conference Proceedings; AIP Publishing LLC: Melville, NY, USA, 2017.

3. Zunita, M.; Makertihartha, I.; Saputra, F.; Syaifi, Y.; Wenten, I. Metal Oxide based Antibacterial Membrane. In IOP Conf. Series: Materials Science and Engineering; IOP Publishing Ltd.: Bristol, UK, 2018.

4. Fontana, M.G. Corrosion Engineering, 3rd ed.; McGraw-Hill Science, Engineering \& Mathematics: London, UK, 1986; pp. 373-377.

5. Stupnišek-Lisac, E.; Božić, A.L.; Cafuk, I. Low-toxicity copper corrosion inhibitors. Corrosion 1998, 54, 713-720. [CrossRef]

6. Raval, D.; Mannari, V. Imidazoline Derivatives as Corrosion-Inhibitors. Res. Ind. 1994, 39, 94-95.

7. Zhang, Q.; Hua, Y. Corrosion inhibition of mild steel by alkylimidazolium ionic liquids in hydrochloric acid. Electrochim. Acta 2009, 54, 1881-1887. [CrossRef]

8. Likhanova, N.V.; Arellanes-Lozada, P.; Olivares-Xometl, O.; Hernández-Cocoletzi, H. Effect of organic anions on ionic liquids as corrosion inhibitors of steel in sulfuric acid solution. J. Mol. Liq. 2019, 279, 267-278. [CrossRef]

9. Kowsari, E.; Payami, M.; Amini, R.; Ramezanzadeh, B.; Javanbakht, M. Task-specific ionic liquid as a new green inhibitor of mild steel corrosion. Appl. Surf. Sci. 2014, 289, 478-486. [CrossRef]

10. Şafak, S.; Duran, B.; Yurt, A.; Türkoğlu, G. Schiff bases as corrosion inhibitor for aluminium in $\mathrm{HCl}$ solution. Corros. Sci. 2012, 54, 251-259. [CrossRef]

11. Zunita, M.; Wahyuningrum, D.; Buchari, B.B.; Bundjali, B. Investigation of corrosion inhibition activity of 3-butyl-2, 4, 5-triphenylimidazole and 3-butyl-2-(2-butoxyphenyl)-4, 5-diphenylimidazole toward carbon steel in $1 \% \mathrm{NaCl}$ solution. Int. J. Electrochem. Sci. 2012, 7, 3274-3288. 
12. Makertihartha, I.; Zunita, M.; Rizki, Z.; Dharmawijaya, P. Recent advances on zeolite modification for direct alcohol fuel cells (DAFCs). In AIP Conference Proceedings; AIP Publishing LLC: Melville, NY, USA, 2017.

13. Schmitzhaus, T.E.; Ortega Vega, M.R.; Schroeder, R.; Muller, I.L.; Mattedi, S.; Malfatti, C.D.F. An amino-based protic ionic liquid as a corrosion inhibitor of mild steel in aqueous chloride solutions. Mater. Corros. 2020, 71, 1-19. [CrossRef]

14. Elayyachy, M.; El Idrissi, A.; Hammouti, B. New thio-compounds as corrosion inhibitor for steel in $1 \mathrm{M} \mathrm{HCl}$. Corros. Sci. 2006, 48, 2470-2479. [CrossRef]

15. Lv, B.; Wu, K.; Zhou, Z.; Jing, G. How did the corrosion inhibitor work in amino-functionalized ionic liquids for $\mathrm{CO}_{2}$ capture: Quantum chemical calculation and experimental. Int. J. Greenh. Gas Control 2019, 91, 102846. [CrossRef]

16. Ashassi-Sorkhabi, H.; Es'Haghi, M. Corrosion inhibition of mild steel in acidic media by [BMIm] Br Ionic liquid. Mater. Chem. Phys. 2009, 114, 267-271. [CrossRef]

17. Seter, M.; Thomson, M.J.; Stoimenovski, J.; MacFarlane, D.R.; Forsyth, M. Dual active ionic liquids and organic salts for inhibition of microbially influenced corrosion. Chem. Commun. 2012, 48, 5983-5985. [CrossRef] [PubMed]

18. Verma, C.; Ebenso, E.E.; Quraishi, M. Ionic liquids as green and sustainable corrosion inhibitors for metals and alloys: An overview. J. Mol. Liq. 2017, 233, 403-414. [CrossRef]

19. Jenkins, A.; Mok, W.; Gamble, C.; Dicken, G. Development of green corrosion inhibitors for preventing under deposit and weld corrosion. In Proceedings of the SPE International Symposium on Oilfield Corrosion, Aberdeen, UK, 28 May 2004.

20. Guo, Y.; Chen, Z.; Zuo, Y.; Chen, Y.; Yang, W.; Xu, B. Ionic liquids with two typical hydrophobic anions as acidic corrosion inhibitors. J. Mol. Liq. 2018, 269, 886-895. [CrossRef]

21. Ardakani, E.K.; Kowsari, E.; Ehsani, A. Imidazolium-derived polymeric ionic liquid as a green inhibitor for corrosion inhibition of mild steel in $1.0 \mathrm{M} \mathrm{HCl}$ : Experimental and computational study. Colloids Surf. A Physicochem. Eng. Asp. 2020, 586, 124195. [CrossRef]

22. Asefi, D.; Mahmoodi, N.M.; Arami, M. Effect of nonionic co-surfactants on corrosion inhibition effect of cationic gemini surfactant. Colloids Surf. A Physicochem. Eng. Asp. 2010, 355, 183-186. [CrossRef]

23. Dong, B.; Zhao, X.; Zheng, L.; Zhang, J.; Li, N.; Inoue, T. Aggregation behavior of long-chain imidazolium ionic liquids in aqueous solution: Micellization and characterization of micelle microenvironment. Colloids Surf. A Physicochem. Eng. Asp. 2008, 317, 666-672. [CrossRef]

24. Makertihartha, I.; Zunita, M.; Rizki, Z.; Dharmawijaya, P. Solvent extraction of gold using ionic liquid based process. In AIP Conference Proceedings; AIP Publishing LLC: Melville, NY, USA, 2017.

25. Zunita, M.; Wahyuningrum, D.; Bundjali, B.; Wenten, I.G.; Boopathy, R. The Performance of 1, 3-Dipropyl2-(2-propoxyphenyl)-4, 5-diphenylimidazolium Iodide based Ionic Liquid for Biomass Conversion into Levulinic Acid and Formic Acid. Bioresour. Technol. 2020, 123864. [CrossRef]

26. Welton, T. Ionic liquids: A brief history. Biophys. Rev. 2018, 10, 691-706. [CrossRef]

27. Mezzetta, A.; Perillo, V.; Guazzelli, L.; Chiappe, C. Thermal behavior analysis as a valuable tool for comparing ionic liquids of different classes. J. Therm. Anal. Calorim. 2019, 138, 3335-3345. [CrossRef]

28. Philippi, F.; Pugh, D.; Rauber, D.; Welton, T.; Hunt, P.A. Conformational design concepts for anions in ionic liquids. Chem. Sci. 2020, 11, 6405-6422. [CrossRef]

29. Cheng, J.-Y.; Chu, Y.-H. 1-Butyl-2, 3-trimethyleneimidazolium bis (trifluoromethylsulfonyl) imide ([b-3C-im][NTf2]): A new, stable ionic liquid. Tetrahedron Lett. 2006, 47, 1575-1579. [CrossRef]

30. Raja, P.B.; Sethuraman, M.G. Natural products as corrosion inhibitor for metals in corrosive media-A review. Mater. Lett. 2008, 62, 113-116. [CrossRef]

31. Makertihartha, I.; Zunita, M.; Dharmawijaya, P.; Wenten, I. Supported ionic liquid membrane in membrane reactor. In AIP Conference Proceedings; AIP Publishing LLC: Melville, NY, USA, 2017.

32. Chiappe, C.; Margari, P.; Mezzetta, A.; Pomelli, C.S.; Koutsoumpos, S.; Papamichael, M.; Giannios, P.; Moutzouris, K. Temperature effects on the viscosity and the wavelength-dependent refractive index of imidazolium-based ionic liquids with a phosphorus-containing anion. Phys. Chem. Chem. Phys. 2017, 19, 8201-8209. [CrossRef] [PubMed]

33. Wilkes, J.S.; Levisky, J.A.; Wilson, R.A.; Hussey, C.L. Dialkylimidazolium chloroaluminate melts: A new class of room-temperature ionic liquids for electrochemistry, spectroscopy and synthesis. Inorg. Chem. 1982, 21, 1263-1264. [CrossRef] 
34. Keskin, S.; Kayrak-Talay, D.; Akman, U.; Hortaçsu, Ö. A review of ionic liquids towards supercritical fluid applications. J. Supercrit. Fluids 2007, 43, 150-180. [CrossRef]

35. Loveday, D.; Peterson, P.; Rodgers, B. Evaluation of organic coatings with electrochemical impedance spectroscopy. JCT Coat. Tech. 2004, 8, 46-52.

36. Popova, A.; Christov, M.; Raicheva, S.; Sokolova, E. Adsorption and inhibitive properties of benzimidazole derivatives in acid mild steel corrosion. Corros. Sci. 2004, 46, 1333-1350. [CrossRef]

37. Hartanto, Y.; Yaswari, Y.; Zunita, M.; Soerawidjaja, T.H.; Indarto, A. Decolorization of crude terpineol by adsorption. Sep. Sci. Technol. 2017, 52, 1967-1972. [CrossRef]

38. Goldberg, S.; Tabatabai, M.; Sparks, D.; Al-Amoodi, L.; Dick, W. Equations and models describing adsorption processes in soils. Soil Sci. Soc. Am. Book Ser. 2005, 8, 489.

39. Choy, K.K.; McKay, G.; Porter, J.F. Sorption of acid dyes from effluents using activated carbon. Resour. Conserv. Recycl. 1999, 27, 57-71. [CrossRef]

40. Cao, S.; Liu, D.; Ding, H.; Wang, J.; Lu, H.; Gui, J. Task-specific ionic liquids as corrosion inhibitors on carbon steel in $0.5 \mathrm{M} \mathrm{HCl}$ solution: An experimental and theoretical study. Corros. Sci. 2019, 153, 301-313. [CrossRef]

41. Ahmed, S.A.; Awad, M.I.; Althagafi, I.I.; Altass, H.M.; Morad, M.; Alharbi, A.; Obaid, R.J. Newly synthesized indolium-based ionic liquids as unprecedented inhibitors for the corrosion of mild steel in acid medium. J. Mol. Liq. 2019, 291, 111356. [CrossRef]

42. Lyubchik, S.; Lyubchik, A.; Lygina, O.; Lyubchik, S.; Fonseca, I. Comparison of the thermodynamic parameters estimation for the adsorption process of the metals from liquid phase on activated carbons. In Thermodynamics-Interaction Studies-Solids, Liquids and Gases; IntechOpen: Rijeka, Croatia, 2011.

43. Wang, J.-T.; Meng, P.-J.; Chen, Y.-Y.; Chen, C.A. Determination of the thermal tolerance of Symbiodinium using the activation energy for inhibiting photosystem II activity. Zool. Stud. 2012, 51, 137-142.

(C) 2020 by the authors. Licensee MDPI, Basel, Switzerland. This article is an open access article distributed under the terms and conditions of the Creative Commons Attribution (CC BY) license (http://creativecommons.org/licenses/by/4.0/). 